\title{
CONFERENCE OF MUNICIPAL AND COUNTY ENGINEERS.
}

\section{ADDRESS}

BY FRANCIS J. C. MAY, M.Inst.C.E., Borough Engineer and Surveyur, Brighton.

PRESIDENT OF THE CONFERENCE.

Is opening the proceedings of this Conference of Municipal Engineers held under the auspices of the Sanitary Institute, I wish it to be clearly understood that we are not present to represent the corporate body of Municipal and County Engineers, but as individual members of a profession, and engaged in the particular branch of that profession which deals chiefly with matters relating to the public health. We are here as municipal engineer's, each in his own sphere of labour, interested in securing the lighest degree of sanitation in the town forming that sphere of labour.

Parliament has invested the Local Goverment Board, among its other duties, with the administration of the public health throughout the land; and it has hitherto performed those duties wonderfully well; but the subject is one that grows in magnitude, and of which the details of the duties increase every year, so that I think the public health department should now have a separate existence from the Local Government Board, under a recognised chief, who, as Minister of Public Health, should have a seat in the Cabinet.

We serve those local authorities, who, under the control and direction of the Local Government Board, are entrusted by parliament with the care and guardianship of the public health throughout the length and breadth of the kingdom. We recognize the fact, that the health of the people is a subject which concerns not only the government, and the local authorities, nor one set of persons or one profession; but that it is a matter in which the desired results can only be acquired by the joint action and co-operation of many parties and professions. 
The care and supervision of the government and local authorities-the efforts of those in high position in the land, and with leisure at their command, who desire to help from a humanitarian point of view-of the clergy, and others whose calling leads them into the vilest slums and alleys of our towns, or into the by-ways of our country parishes, where houses are in an insanitary condition, where water is scarce and of low quality, and where a low order of the necessities of life generally prevailsof the medical profession individually, who with their scientific knowledge, coupled with their generous and often gratuitous labours among the indigent poor, have opportunities of learning the condition of their lives and surroundings-but more especially of that branch of the medical profession with whom we are closely allied in municipal life,-the medical officers of health-of the engineering profession to which we have the honour to belong- of the public sanitary officers of every degree. The hearty co-operation of these various professions, or sections of society is needed in order to accomplish a ligher standard of public health. Each and all of these various sections of society are represented at the present Congress. We willingly join them to show our sympathy with, and desire to help, so far as in us lies, that good work which aims at the reduction of sickness and distress, the prolongation of life, and the rendering of that life easier and happier, by ascertaining and adopting the best known means to improve the morals, the health, the dwellings, and the surroundings generally, of the whole community. Much has been done during the list fifty years to improve the general conditions of the health of our land. The Sanitary Institute, the Britisl Institute of Public Health, and other lindred societies, have done much to bring about this improvement, but much more remains to be done. The general public need much more further awakening and education in this subject.

We require, from honest conviction of the necessities of the case, the hearty co-operation of individual owners and occupiers of property, and even of every individual of society. How much faster would be the progress of sanitation, if it were only taken up seriously by individuals, each in their own home or locality. I believe that meetings, such as the Congress that is being held here at the present time, and all such others, are the best means of collecting and spreading further kmowledge for improving all the conditions of health and life. I therefore cheerfully accepted the invitation to preside over a conference of municipal engineers, in connection with it; and I assume that such were the motives that led you to favour us by your attendance here to-day. 
We do not claim that all the desired results in sanitary matters are to be attained by the efforts of the engineering profession, neither cau we admit that the medical profession, or any other section of the community alone, can secure them. Medical men must agree, and be content to work side by side with engineers, and all other professions and sections of the community having the common weal in view. All should join hand in liand, and work shoulder to shoulder, without envy or jealousy, in such a good cause. The only rivalry permitted or acknowledged in this matter should be the rivalry of good works and words, each candidly acknowledging the good work done by the other, and thereby cheering and encouraging each other in still further good works.

Having laid down these general views of the subject, I will now proceed to see in what manner we municipal and county engineers can help forward this noble work.

The local authorities, urban, rural and county, whom we serve, are, as I have already said, the responsible bodies on whom devolves the eluty of guarding the public health. We of ten hare to advise our authorities on technical matters relating to the public health, and afterwards have to carry out their instructions. How important it is, therefore, that we should thoronghly understand, even to the most minute cletail, everything that pertains to sanitary engineering in relation to the public health; and it is, in my opinion, equally necessary that the municipal engineer should have very strong and earnest sympathies with the object, to ensure his whole heart being engaged in his work, so that he may make every effort to be in a position to know, to understand, and to recommend the adoption of the latest revelations of science, or research, for the public weal.

It is impossible, in such a short address as this must necessarily be, to touch upon all the subjects which are embraced within the meaning of the term "Sanitary Engrineering," as implied under the requirements of the Public Health $\Lambda$ cts, but I will briefly refer to some which I consider the most important. These are;-

1. Water Supply.

2. Healthy Dwellings, embracing inspection of new houses during construction; the removal and disposal of house refuse; the removal of nuisances.

3. Sewerage and Drainage, embracing inspection of the construction, and subsequent testing of sewers and house drains, and of the various connections therewith. 


\section{Sewage Disposal Works.}

5. Ventilation of Sewers and House Drains.

6. The Construction of good Roads and Impervious Pavements, thorough Scavenging, \&c.

\section{Water Supply.}

I do not propose to enlarge very much upon this subject. We all recognise it as a very important one, but as a rule the supply and distribution of water is outside the purview of the municipal engineer and surveyor, per se, and is controlled by the waterworks engineer, the head of a separate department, either under municipal or private government.

One of the most imperative cluties of a local authority is to secure and provide an abundant supply of pure water. It is an absolute necessity of health and life, and one as to which economy in its use should be religiously observed. Waste of this essential of life in the household is a sin, and one the waterworks engineer takes steps to check as much as possible. How much greater is the transgression in factories, and places where the demand is greater, and where the means of supervision are correspondingly less. We all know how much the people need to be educated in the virtue of economy in this respect.

I feel, therefore, that the distinct duty devolves upon the municipal engineer to regard the water supply as a commodity of the highest value; to do all he can to prevent waste in every section of his department; and to restrict its use to that of absolute necessity only. In all building operations, for use in urinals, flushing sewers, street watering, and all such like purposes, the strictest economy should prevail. In many places sea or river water might be used for some purposes; and, I think, too, that our attention might profitably be turned towards the collection and storage of rain and flood waters for many purposes. By following out these suggestions we shall all be working in harmony with the waterworks engineer for the common good; and we should do so just as much as if we were ourselves personally engaged in the question of supply and distribution of this most essential element of health and life.

\section{Healthy Dwellings.}

a. Inspection of Houses during Construction. I am of opinion that in most cases the building bye-laws are sufficiently stringent for the construction of sanitary houses if carried out strictly; 
but I think the general experience is, that local authorities do not give the local surveyor sufficient assistance to ensure them being carried into effect in their entirety. I think this is a matter which needs to be brought more prominently under the notice of local authorities; and further measures should be adopted to secure efficient supervision at all times.

b. The Removal and Disposal of House Refuse. This is a most essential element in relation to our efforts to secure healthy dwellings, especially among the poorest part of our population. I think it is a great pity that the law does not compel the construction of a back passage for all small property, so as to avoid the necessity for any drain to pass under a house; and to afford facilities for the removal of ashes, and all other kinds of refuse, without carrying it all through the dwelling. It is done, I know, in many of the large towns of the midland and northern counties with good effect. It is not general in the towns in which I have had to work, and I therefore know the great disadvantage of the omission, and the great need for this to be marle a compulsory measure. In cases where there is a weekly collection it often happens that the dustmen call when the occupiers are from home, at work, or after the house has been cleaned up, or on a washing and ironing day; cases in which it is either impossible or undesirable from the housewife's point of view, for the ashes to be removed; and so, notwithstanding all the sood arrangements made by the local authorities, the ashes are frequently allowed to accumulate for several weeks before removal. This would not occur if the back passage system were adopted. From my experience I have almost come to the conclusion that a daily removal of house refuse in the denser parts of the town is almost a necessity; and if the occupiers were compelled to place their receptables on the pavement before a certain hour in the morning, I believe it would be possible to collect it as cheaply as it is done now weekly by the dustman going through the house to bring it out. I should most readily join in any movement set on foot to bring about the general adoption of the back passage system; it being in $\mathrm{my}$ opinion most decidedly the best from a sanitary point of view.

On the subject of the "disposal" of the refuse, I think there can only be one opinion, viz., that all such useless and vile products should be consumed by fire and rendered imnocuous. It is, however, a somewhat costly process, and it is useless to think of making a substantial profit out of the residue, although sometimes it is used for making up roads and footpaths, concrete, paring slabs, \&c. The amount of the residue is so great that only a small proportion can be utilized in this manner. All hope of realizing profit from the working of a destructor 
will lead only to disappointment. The question of "Disposal of House Refuse" must be at once regarded as a necessary expenditure, entailing direct loss to the ratepayers financially, but one which is amply repaid indirectly by the reduction of sickness, or distress, and of the death rate, due to the improved conditions of the atmosphere of the dwelling and its surroundings. The ingenuity of all municipal engineers should be directed towards the adoption of all such means as local circumstances will admit to reduce the financial loss to a minimum sum.

The attention of engineers is therefore now being well employed in devising schemes for storing and utilizing the heat produced by the act of combustion, so as, if possible, in this way to reduce the cost of disposal of refuse. Further progress in this direction is in my opinion much needed, and as time goes on further experience will develope new ideas and means. I commend this point to the careful consideration of all those who are contemplating the use of a refuse destructor.

c. The Remocal of Nuisances. I intend to pass this by with a very few remarks, as $I$ consider it is one that more properly belongs to the health department, than to the surveyor's department. The medical officers of health, and their staff of sanitary inspectors, are carrying on the crusade against nuisances in most cases in a splendid manner.

In the town with which I am associated, it is most essentially so, and I feel it my duty whenever an opportunity permits the remarks, to bear my testimony to the fact, that, in my town (Brighton) there is perfect unanimity of feeling between the officers of the health, and the engineer and surveyor's departments, so that we are able to work side by side, assisting and encouraging each other in the most friendly manner. This is as it should be, and I hope it is general, or will become so, throughout the land.

\section{Seiverage and Drainage.}

a. The Construction of Sewers and Drains, Inspection and Testing. This is a matter which may truly be said to be one that belongs in a peculiar manner solely to the municipal engineer. It is most essential that all our work in relation thereto, should be of the very best and truest character. Good workmanship, and absolute truth in the lines and levels, the best of materials of all kinds, and thoroughly watertight sewers and drains, should always be insisted upon. All sewers and house drains should be tested in the severest manner, by the water test. 
Whether the subsoil water should first be drained off-the kind of joint to be used to secure the best results uncler the most trying circumstances-whether the sewer or drain must be embedded wholly or partially in concrete, and all such other matters of detail must be left to the intelligence of the engineer responsible for the work. I think that most failures in any of these respects, whether in sewers or house drains, are due more to a lack of proper supervision, than to any other cause; and I would strongly urge upon all engineers engaged in this work, to insist upon having a proper staff of assistants of the rarious grades to ensure a faithiful adherence to the specifications and plans, which are usually prepared with consummate care, only to be rendered inoperative for want of efficient supervision. The members of Local Authorities are usually men of business and experience, and will generally recognise the folly of parsimony in such matters, if the engineer will only introduce the question with tact and cliscretion.

It is in my opinion a subject for extreme regret, that, as the law stands at present, it is a moral impossibility in most cases to insist upon the system of back drainage. Local authorities are almost compelled, in self-defence, to insist upon the separate drainage of each house. This of course, in the majority of cases, entails the necessity for taking the drain through the house. Of course, every one knows it is possible to construct a water-tight drain, and we all endeavour to insure it is so, but we cannot guarantee that it will ever remain so. It may be upset by many accidents, quite unknown to, and unavoidable by the sanitary authority, or its officers. I have met with many such instances, and doubtless most of you have also experienced them, and the evil consequences that have followed. These consequences could not have arisen if the drain had not been allowed to be constructed inside the house. I cannot help thinking that the time has come for all parties interested in the public health, to co-opcrate so as to bring such pressure to bear upon the govermment, as shall lead to a speedy alteration of the law in this respect. Every sensible man admits that it is only common sense to keep all drains out of the house, and yet the law of the land alone prevents the practice. It will be better for the public when the law of common sense prevails. Let us all do what we can to bring it about.

\section{Sewage Disposal.}

This I still consider one of the most difficult problems of the present day, notwithstanding all the experiments and experience gained during the last 25 years. It is one which every 
engineer, or surveyor of a local authority, has, in some measure or other, to deal with. It is therefore incumbent upon us all to take advantage of every opportunity for educating ourselves on this subject, in all its several bearings and details. It is a subject which permits of no universal method of treatment. It is governed almost entirely by local circumstances, relating to the nature of the soil and subsoil-the position of the locality and its surroundings - the nature of the trade, and the habits of the community, among other circumstances too numerous to mention. Local authorities of towns on the borders of our seas, or rivers, avail themselves largely of the facilities for discharging their sewage into the waters; some in its crucle condition, others more or less treated by mechanical, or chemical methods, to remove the solids, and to purify the eflluent.

Other authorities of towns or villages not so fortunately situated, are dependent solely upon those methods which have been devised for disposing of both solid and liquid sewagre on the land, mostly in connection with the water-carriage system.

The first method I consider a barbarous, although cheap, method of disposal. I am not inclined to find much fault with local authorities for adopting it, as I consider it is the most sensible way of dealing with the sewage, where it can be clone without harm to others, under the present unsatisfactory state of the question. I do, however, think it is incumbent upon all engineers concerned with this subject, to endeavour to devise some more satisfactory method of disposal. I am strongly of opinion that our attention should be given, as much as possible, to devise some means whereby all fœcal matter, urine, \&c., may be returned to the land in its natural condition, to fertilize it, and to repay with interest that which has been taken from it. This cannot be done so long as we rely almost wholly on the water carriage system. A system which while it affords the readiest meaus of removal of our filth, also rlestroys all its great manurial value, and is, in my opinion, a sinful waste of the products of nature. I think that the combined efforts of the scientific chemists and engineers are required, the one to render such matter in the dwelling at once innocnons and inodorous, the other to devise some ready means for its discharge therefrom into suitable receptables, which may be removed daily and conveyed direct to the land, without in any way creating a nuisance. I think that pneumatic or electric power should in future be so easily manipulated, as to enable future engineers to accomplish this purpose.

Seeing what a valuable commodity water is, how difficult and expensive it is to obtain a plentiful supply at the present time, and how the absolutely necessary consumption must largely

VOL. XVII. PART III. 
increase with the rapid growth of our population, the time, in my opinion, is not far distant when the large consumption of pure and clean water now expended on the water-carriage method of removal of excrementitious matter, \&c., will be considered a wilful waste; and public opinion will demand from engineers, that some more scientific and rational method shall be devised by them. As one having had experience of both the first and second methods, I am able to say, from my own experience, with reference to the second method, that, in my opinion, there has not yet been devised a wholly satisfactory system for the application of sewage to the land, in such a condition as to obtain the fullest beneficial results from this waste product of animal life. It is not my intention to make distinctions between the several methods that are in vogue, or to advocate one system in preference to another, but I wish only to remark, that, in my opinion, the great cause of failure in each case is the increase of volume and the loss of value, consequent upon the dilution effected by the water-carriage system. I therefore feel convinced that a great revolution of opinion and practice will eventually arise, and that future generations will be astonished at our insane waste of the valuable products of animal life, so necessary for the reproduction of vegetable life; and at our ignorance in using such a valuable necessity of life, as pure water, to enable us easily to effect that waste. I regard this question as one of the most important that should engage the attention of engineers and local authorities entrusted with the health, wealth, and prosperity of the whole community.

It is one well worthy of the best labours and intellect of both chemists and engineers in the interest of public health; and as one which will bring to them its own reward, in increased and increasing opportunities for work and practice.

\section{The Ventilation of Sewers and Drains.}

I feel that in this $I$ am launching into troubled waters. Notwithstanding all that has hitherto been said or written upon this vexed question it still remains in an unsettled condition, and I am of opinion that it will long continue so. It is one that depends so much upon varying local circumstances that it is impossible to lay down any hard and fast rule. The information that has been given in reference to this question has been of a very conflicting nature, and I think it is high time that investigations should be undertaken by some competent authority in a businesslike and systematic way, and upon some established basis extended over a large area, and for a long 
period. It is only in this way that such statistics can be gained as will give reliable results. My own opinion, after many years of experience, is that the freest ventilation possible combined with thorough and regular flushing is the best-that grids in the roadway should only be placed in such positions as will enable them to act as air inlets, and not as outlet ventilators; that ventilation should be carried out mainly by means of shafts, of ample area, attached to high houses or buildings. This is the principle that I have been carying out during the last seven years with great success. I have usually been able to secure sites for ventilators, by arrangements with owners of property, on very reasonable terms. The ventilators being built entirely by my own workmen, on my own plan, designed in such a manner that the shaft appears to be a part of the building to which it is attached, and therefore it does not become an eyesore to the owner or occupier of the building. Care is always taken that it is built in such a manner that it is wholly clistinct from the house; so that it is impossible for sewer air in any way to penetrate it, or to escape into, or to be drawn into it.

I have also introduced with much advantage balanced check valves at different places near a ventilating shaft, to prevent the sewer air of the low levels passing to the higher levels, when the velocity of air in the sewer is very great. Whenever $I$ have had complaints of a street grid being offensive, instead of closing it, I have sought a suitable site near for a vertical shaft, and when this has been built the alleged nuisance from the street grid has ceasecl, and it has been found to act as an air inlet instead. On the house drains it has always been my practice to place an intercepting trap between the house and the sewer. I consider that the ventilation of the sewer should be self-contained, and should not require the house drain to serve as a ventilator for the sewer. I think it is not fair to cast this burden and responsibility on private owners. I also consider the practice very objectionable and dangerous, when, as is generally the case in large towns, the house drain passes under and through the house itself. Immediately behind the intercepting trap in front of the house, the fresh air inlet should be placed, and there should be no obstruction between it and the ventilating shaft at the rear, then I think we may feel that all has been done to secure a regular current of fresh air throughout the house drainage. I think it is better to depend upon natural ventilation, with exhaust cowls where necessary, than upon any mechanical system that has yet been devised. I am convinced, too, that it is not prudent to rest for ever contented, after knowing that the house drainage and ventilation has been 
satisfactorily constructed. All houses should be periodically inspected by competent officials to detect those accidents by which the initial arrangements are frequently upset, and to ensure that everytling is remaining in working order. All amendments, alterations or restorations found to be necessary should be supervised by the engineer's' or surveyors' department under whose direction the system was originally designed, approved or constructed.

\section{Construction of Good Roads and Impervious Footways, Scavenging, \&c.}

This section of our work is, in my opinion, by no means the least important as a factor in the condition of the public health. Good roads, properly constructed, from which the rainfall is most easily drained, and from which the debris and filth is most readily removed from the surface, help to reduce the moisture so detrimental to health. I do not propose now to enter into any description or comparison of the relative values or merits of the various kinds of materials in use, nor to speak on the subject from economic grounds. I merely wish, at this sanitary meeting, to emphasise the fact that this is a subject to which engineers would do well to devote much more attention than is frequently the case, from a sauitary standpoint alone. The more impervious the roadway is, the better is its sanitary condition, and this quality should be constantly aimed at. There has been a great improvement generally during recent years, and a higher standard is undoubtedly required now than at any previous time, owing largely to the introduction of cycling. The further introduction of auto-cars, \&c., will doubtless lead us all to aim at still greater perfection in the surface of all carriage-ways.

The better the condition of the road surface, the more easily and efficiently it is scavenged. The more cleanly the roads are kept, the better it is for the health and temper of the people. The more even the surface, the less is the wear and tear of carriages and horses, bicycles, and motor cars. This question is therefore becoming more than ever one in which all classes of the community are concerned. The higher standard of perfection required leads to a corresponding increase of expenditure, but there is also indirectly a like saving of expense as a set-off against it, in the reduction of the wear and tear of the property of the individuals who use the roads-as nearly everyone now does-by one or other of the before-mentioned means of locomotion. There is every reason, therefore, for engineers to consider and to study this subject in a scientific 
manner now, as Telford, Macadam, and other eminent engineers did in the early part of the century.

The question of footway pavements I propose to treat also from the same sanitary standpoint only. In reference to them I have only to remark that I consider it to be, in towns especially, most important that they be of such a character, and laid in such a manner as to keep the basements as dry as possible. This is most essential when they are used as living rooms; and it is scarcely less so when otherwise, for the damp air of the basement must, at times, more or less affect the general condition of the air of the whole dwelling. Without expressing any opinion of the merits or demerits of the various kinds of pavements in use, I recommend the adoption of those which are non-absorbent, and which can be laid with the smallest number of joints. There are, of course, many that answer this description, but they vary in cost; the municipal engineer should make his selection having regard to the local conditions of traffic, situation, gradient, character of the neighbourhood, \&c., in addition to the initial cost, and that of the probable repairs.

The foregoing subjects are some of those relating to the sanitation of towns and villages, which lie within the compass of the claily duties of the engineer or surveyor. There are of course many others, equally important, of which time will not permit me to speak in this address, such as the construction of artisans' dwellings, municipal common lodging houses, sanatoriums, or isolation hospitals, public abattoirs, mortuaries, cemeteries, and even crematories, \&c., \&c.

I trust, however, that I have said sufficient to prove the necessity for the municipal or local engineer and surveyor to have his heart and sympathy engaged in the duties of his office, from a humanitarian point of view, as well as to keep his professional knowledge well abreast of the times, seeing how largely he may be able by his personal skill, and intelligence, to assist and forward the great work that the local authorities, The Sanitary Institute, other kindred associations and philanthropic persons clesire to promote. Also, that we, and the members of the various other professions engaged in the same work, should agree to work together with harmony and goodwill, not trenching upon each other's duties, or positions, whereby one or the other may feel offended, but working shoulder to shoulder in support of each other, for the common weal.

I must now conclude, feeling that I have left much unsaid which might have been enlarged upon if the time had permitted, still hoping that I may have said quite sufficient to prove that the engineer plays a very important part in the work 
of sanitation, and to encourage others, as well as ourselves, not to be weary in well doing in our several spheres; but to do all that we have to do with our very best efforts, not only for onr own personal or professional interests ; but from higher motives still, remembering that it is only by the concert of all our individual efforts, that the sanitary condition of our country can be perfected, and those desirable objects-improved health, increased happiness, and longevity of our fellow-beings can be secured.

Finally, I trust that this Congress of the Sanitary Institute will also have the effect of educating the people still further on this important subject, and stimulating them to action, by shewing them how much can be done to promote the health of the whole community by the individual who will take an intelligent interest in his own surroundings. 